\title{
Long noncoding RNA SNHG1 promotes TERT expression by sponging miR-18b-5p in brease
}

\section{cancer}

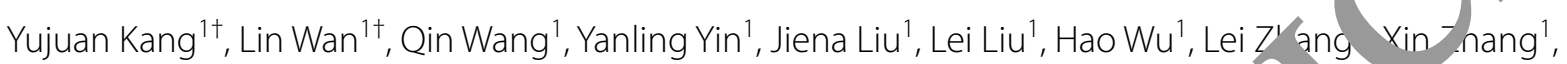

Shouping $\mathrm{Xu}^{1^{*}}$ and Da Pang ${ }^{1,2^{*}}$ (D)

\begin{abstract}
Background: Long noncoding RNA (IncRNA) small nucleolar RNA hos+ gene 1 ( 'iG1) plays a positive role in the progression of human malignant tumors. However, the molecular meci arm of SNHG1 remains elusive in breast cancer.
\end{abstract}

Results: LnCRNA SNHG1 was upregulated and had a positive+tionship with poor prognosis according to bioinformatics analysis in pan-cancer including breast cancer. Siler ing SN, G1 inhibited tumorigenesis in breast cancer both in vitro and in vivo. Mechanistically, SNHG1 functioned a c npet.ng endogenous RNA (ceRNA) to promote TERT expression by sponging miR-18b-5p in breast cance mif 18b-5, acted as a tumor repressor in breast cancer. Moreover, the combination of SNHG1 knockdown and TER aibitc administration showed a synergistic inhibitory effect on breast cancer growth in vivo. Finally, E2F1 7 transcl, on factor, binding to SNHG1 promoter and enhanced SNHG1 transcription in breast cancer.

Conclusions: Our results provide a co nprehensive anderstanding of the oncogenic mechanism of IncRNA SNHG1 in breast cancer. Importantly, we ident ed a nc vel E2F1-SNHG1-miR-18b-5p-TERT axis, which may be a potential therapeutic target for breast cancer. Ou o also provided a potential treatment for breast cancer when knockdown SNHG1 and TERT inhibitor an intration simultaneously.

Keywords: SNHG1, TERT, Rreast C ncer, Competing endogenous RNA, E2F1

\section{Background}

Long noncodin $\mathrm{R} \Lambda$ \& (lnckNAs) are a large family of RNAs with imited pr ein-coding potential, length of over 200 lecades, and lack of a detectable open reading frame [1- Ir portantly, lncRNA dysregulation has bee ob erved $\Lambda$ various cancers, and they reportedly partic ate ... cancer cell growth, metastasis, and drug resistanc $[6,7]$. Moreover, lncRNAs are a novel class of

\footnotetext{
*Correspondence: Shoupingxu@hrbmu.edu.cn; pangda@ems.hrbmu.edu.cn

${ }^{\dagger}$ Yujuan Kang and Lin Wan contributed equally to this work

${ }^{1}$ Department of Breast Surgery, Harbin Medical University Cancer Hospital, Harbin 150040, China

Full list of author information is available at the end of the article
}

potential biomarkers and therapeutic targets for cancer treatment [8]. In terms of regulatory mechanisms, when lncRNAs are located in the nucleus, they regulate gene expression by acting as epigenetic modulators [9, 10]; whereas, most lncRNAs in the cytoplasm harbor multiple binding sites for identical microRNAs (miRNAs), and are called competing endogenous RNAs (ceRNAs) [11]. miRNAs are a class of pervasive, conserved, small, noncoding RNAs that act as negative gene regulators to repress the expression of target genes [12]. ceRNAs can sequester miRNAs and protect the target mRNAs from being repressed $[13,14]$. LncRNA small nucleolar RNA host gene 1 (SNHG1) is localized at 11q12.3 and shows upregulated expression in various cancers, including original author(s) and the source, provide a link to the Creative Commons licence, and indicate if changes were made. The images or other third party material in this article are included in the article's Creative Commons licence, unless indicated otherwise in a credit line to the material. If material is not included in the article's Creative Commons licence and your intended use is not permitted by statutory regulation or exceeds the permitted use, you will need to obtain permission directly from the copyright holder. To view a copy of this licence, visit http://creativecommons.org/licenses/by/4.0/. The Creative Commons Public Domain Dedication waiver (http://creativeco mmons.org/publicdomain/zero/1.0/) applies to the data made available in this article, unless otherwise stated in a credit line to the data. 
glioma and lung cancer [15-17]. In addition, SNHG1 reportedly serves as an oncogene in human cancers including breast cancer [18]. For instance, Cui et al. have shown that SNHG1 promotes the progression of pancreatic cancer via the Notch-1 signaling pathway [19]. Pei et al. has showed that interference SNHG1 inhibited the differentiation of Treg cells by promoting miR-448 expression and regulating IDO level, thereby impeding the immune escape of breast cancer [20]. Xiong et al. showed that SNHG1 promotes breast cancer progression by regulating of LMO4 [21]. Li et al. SNHG1 activates HOXA1 expression via sponging miR-193a-5p in breast cancer progression [22]. Zheng et al. SNHG1 contributes to proliferation and invasion by regulating miR-382 in breast cancer [23].

Telomeres are cellular nucleoprotein complexes that maintain chromosomal integrity and genome stability [24]. Telomeres are formed by hexameric repeats of a $5^{\prime}$-TTAGGG-3' sequence ending in a $3^{\prime}$ single-stranded overhang, the G-strand overhang $[25,26]$ that protects the genomic DNA from the continued erosion of telomeres during cell division. Human telomerase is compo a of two main core subunits: TERT, which constitut the catalytic subunit and telomerase RNA componer, wh. provides a template for telomerase elongati, [27-29]. Human TERT protein levels are rate-limiting for to merase activity and telomere length homeo tasis [30]. A positive correlation between TERT mRN expre/sion and telomerase activity has been observed, y suggesting that telomerase is primarily 10 ted by TERT gene expression [28, 31, 32]. In approx rate $90 \%$ of human tumors, telomerase is eit er regu rted or reactivated to maintain the telomeres r merous rounds of cell divisions that are quired $r$ the emergence of malignant and metas itic iseases [33]. In cancer cells, TERT activity show differen upregulation that is possibly due to se al coresses, such as transcriptional regulation, altern R NA splicing, and post-translational modinca ons st $-\mathrm{h}$ as protein phosphorylation [30, 34]. Brea an is one of the leading mortal causes from cancer à ng women worldwide $[35,36]$. Surgery, radiotherapy, chemotherapy and hormone therapy are still the main and common therapeutic approaches to treat breast cancer [37]. It was reported that the mRNA expression of TERT in breast cancer samples has a positive relationship with poor prognosis [38]. However, to date, no studies have determined the mechanism of the relationship between SNHG1 and TERT in breast cancer. T us, in this study, we attempted to elucidate the oncogenic "nctic of SNHG1 in breast cancer. To the best of our kno age, this is the first study to report that a EZF. SNH 1 -miR18b-5p-TERT axis is involved in oreast ca $\circ$, and this axis may be a novel potential th rapeuti target for the same. Moreover, the combin ion 'SN G1 knockdown and TERT inhibitor adm ist ion may be a potential treatment for breast ca, r.

\section{Results}

Expression of $S . \quad$ 'G1 nac upregulated in cancerous tissues and positively relac to poor prognosis

To detern the expression level of SNHG1 in human pan-cance tsisu s, TCGA data was downloaded and analyzed. S IHG1 expression level was higher in thyroid carc ma (1'HCA), stomach adenocarcinoma (STAD), sarcon a (SARC), rectum adenocarcinoma (READ), prosL. a denocarcinoma (PRAD), pheochromocytoma and pay aganglioma (PCPG), lung squamous cell carcinoma LUSC), lung adenocarcinoma (LUAD), liver hepatocellular carcinoma (LIHC), kidney renal papillary cell carcinoma (KIRP), kidney renal clear cell carcinoma (KIRC), kidney chromophobe $(\mathrm{KICH})$, head and neck squamous cell carcinoma (HNSC), esophageal carcinoma (ESCA), colon adenocarcinoma (COAD), cholangiocarcinoma (CHOL), cervical squamous cell carcinoma and endocervical adenocarcinoma (CESC), breast invasive carcinoma (BRCA) (Additional file 3: Table S1), bladder urothelial carcinoma (BLCA) than in normal tissues (Fig. 1a and Additional file 4: Table S2). Furthermore, the expression of SNHG1 was also more upregulated in pan-cancer tissues than in normal tissues (Fig. 1b). We also examined five pairs of breast cancer tissues and normal breast tissues to determine SNHG1 expression and observed that SNHG1 showed higher expression level in breast cancer tissues than in paired normal tissues (Fig. 1c and Additional file 5: Table S3). The PrognoScan database demonstrated that higher expression level of SNHG1 was associated with poor relapse-free survival (RFS) (Fig. 1d), and disease-specific survival (DSS) (Fig. 1e) in patients

\footnotetext{
(See figure on next page.)

Fig. 1 Expression of SNHG1 was upregulated in cancerous tissues and positively related to poor prognosis. a The Cancer Genome Atlas results showed that the expression level of SNHG1 was higher in THCA, STAD, SARC, READ, PRAD, PCPG, LUSC, LUAD, LIHC, KIRP, KIRC, KICH, HNSC, ESCA, COAD, CHOL, CESC, BRCA, BLCA than in normal tissues. b Expression level of SNHG1 was also higher in pan-cancer tissues than in normal tissues. $\mathbf{c}$ Expression level of SNHG1 was higher in breast cancer tissues than in normal tissue ( $N=5$ per group). $\mathbf{d}$, e PrognoScan results showed that higher SNHG1 expression level had a positive association with poor overall survival (OS), relapse-free survival (RFS), and disease-specific survival (DSS) in breast cancer. $\mathbf{f}, \mathbf{g}$ Higher expression level of SNHG1 was related to poorer OS and DSS according to pan-cancer analysis. ${ }^{*} P<0.05$; ${ }^{* *} P<0.01$; ***P $<0.001 ; * * * * P<0.0001$; NS no significance
} 


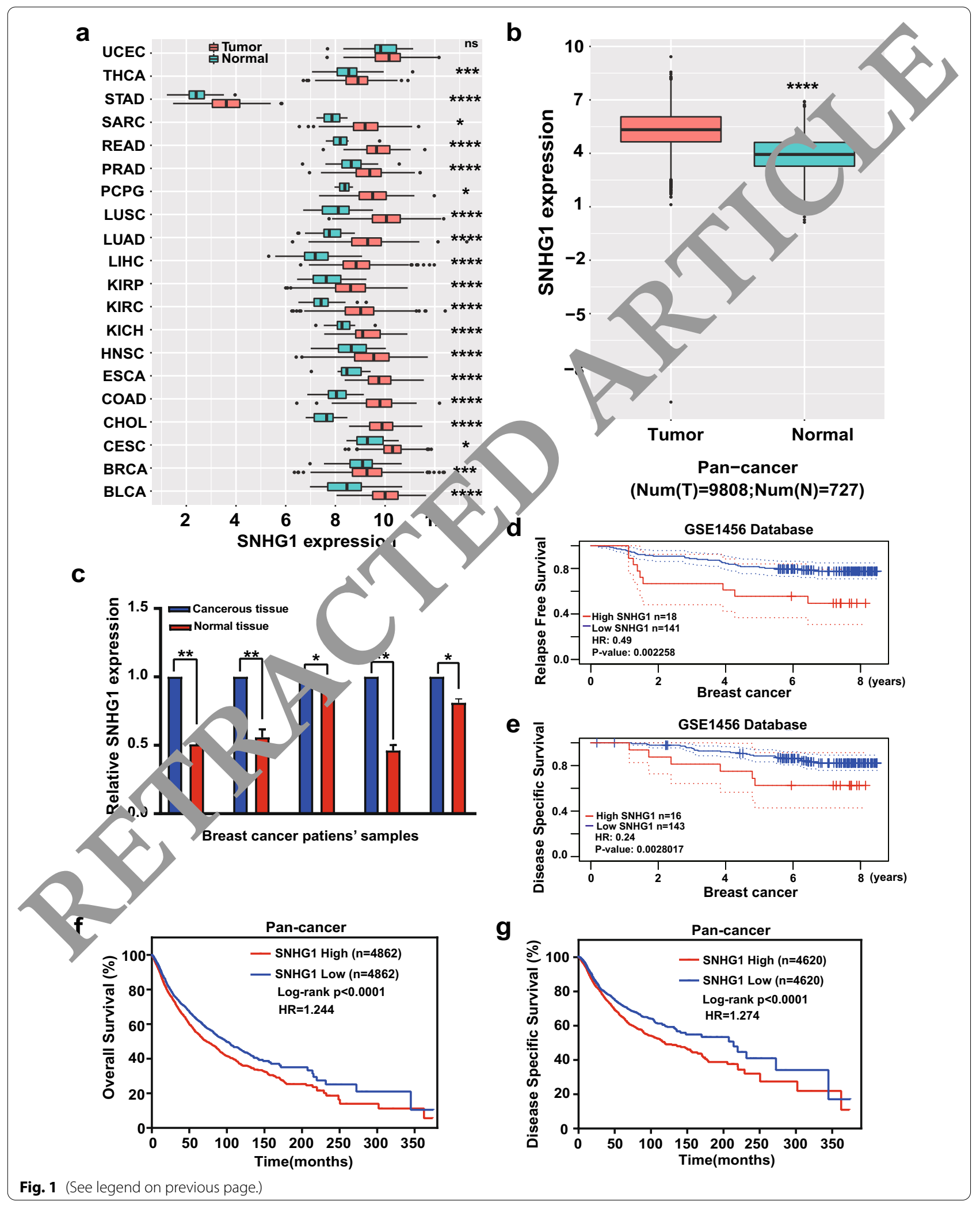


with breast cancer. In pan-cancer analysis, upregulated SNHG1 expression was also related to poor overall survival (OS) and DSS (Fig. 1f, g, Additional file 4: Table S2). Moreover, higher expression of SNHG1 also correlated with poor prognosis in UCEC, LIHC, PRAD, and adrenocortical carcinoma (ACC) (Additional file 1: Fig. S1a-k and Additional file 4: Table S2). We use the KM plotter (http://kmplot.com/analysis/) to evaluate the prognostic value of SNHG1 in different cancers [39]. Higher expression of SNHG1 was correlated with poor OS in LIHC, KIRC, SARC and UCEC (Additional file 1: Fig. S1l-o).

\section{SNHG1 as an oncogene promoted tumorigenesis both in vitro and in vivo}

Hs578T, MDA-MB-468, and MDA-MB-231 are breast cancer cell lines that have higher SNHG1 expression level than MCF10A cells (Fig. 2a); consequently, they were chosen for subsequent experiments. SNHG1 was knocked down by transfection with siSNHG1, and the transfection efficiency of siSNHG1 was evaluated using reverse transcription-polymerase chain reaction (RTPCR) (Fig. 2b). Further, cell counting kit-8 (CCK-8), ony formation, wound healing, and Transwell iny sion assays were performed to identify the function of $\mathrm{NH}_{\mathrm{L}} \mathrm{C}$ in breast cancer. We observed that silencing SNHG. inhibited tumor cell proliferation, colony fo ma $n$ and suppressed tumor cell migration and invasion (Fig. " 2 f).

Subsequently, we evaluated the fun tions of SNHG1 in vivo. Lentivirus was synthesized to nst act a $4 \mathrm{~T} 1$ stable knockdown of snhg1 (. nhg1). Knockdown efficiency was determined usil $g, \mathrm{~K}, \mathrm{PCR}$, and we observed that the virus co. knockdown snhg1 in 4T1, as expected (Fig. 2g). 71 C sh-snhg1 group had poo proliferation ability than the scramble gre ap Fig. 2h) Further, $4 \mathrm{~T} 1$ scramble and 4T1 sh-snhg1 cells $1 r_{2}$ subcutaneously injected into $\mathrm{Balb} / \mathrm{C}$ fer le $\mathrm{n}$ ice. As expected, the mice from the shsnhg1\#3 gro had omaller tumors than those from the scrar IDI yroup 1g. 2i), thereby suggesting that SNHG1 acie 75 ncogene in vivo as well. Moreover, the median mor weight in the sh-snhg1\#3 group was lower than that in the control group (Fig. 2j). The tumorigenesis and tumor tissue of each group of Balb/C mice are shown as Fig. 2k. Furthermore, we pay attention to the relationship between SNHG1 expression and survival. The animal experiment results showed that sh-snhg $\# 3$ group mice have a longer survival compared with "amb' group $(\mathrm{N}=8)$ (Fig. 2l). Thus, the abovementionea alts showed that SNHG1 acted as an oncogo in britast cancer both in vitro and in vivo.

\section{SNHG1 boosted TERT expressi $n$}

Then, TCGA data was downi ded wo evaluate the correlation between $\mathrm{SNH} C$ and $\mathrm{T} . \mathrm{T}$ in pan-cancer and breast cancer. The re lts owed that TERT is positively correlated with $S^{\cdots \times} \mathrm{G} 1$ in $\mathrm{P}$ A-caner scope $(\mathrm{R}=0.2945)$ and breast can sc ne ( $\mathrm{R}=0.3685)$ (Fig. 3a, b and Additional file 6: Tablc 4). In addition, the Gene Expression Profiling ractive malysis (GEPIA) was used to verify this relatic $15{ }_{1}$ and the results showed that TERT was positively co rrelated with SNHG1 (Fig. 3c).

-i. reover, according to SNHG1 gene expression level, RCA cancer tissue samples were divided into o groups: SNHG1 high expression group SNHG1 low exp ession group. We identified a total of 595 differential xpressed genes (FDR $<0.01$, fold change $>1.2)$, among which 456 genes were upregulated and 139 genes were downregulated (Fig. 3d, e and Additional file 7: Table S5). TERT gene was upregulated expressed between high group and low group with FDR $=4.45785008467688 \mathrm{e}-19$, $\mathrm{FC}=0.418132443350429$. As TERT was a certain target gene of SNHG1 in breast cancer, we select it as the SNHG1 downstream gene.

The GEPIA database showed that TERT expression level was considerably higher in breast cancer tissues than in normal tissues (Fig. 3f). Just as Fig. 3g showed, TERT presents a higher expression level in breast cancer cell lines than in MCF10A cell. We then examined four pairs of breast cancer tissues and normal breast tissues to determine TERT expression and observed that TERT showed higher expression level in breast cancer tissues than in paired normal tissues (Fig. $3 \mathrm{~h}$ and Additional file 5: Table S3). Moreover, CCK-8, colony formation and wound healing assays were performed to identify

\footnotetext{
(See figure on next page.)

Fig. 2 SNHG1 acts an oncogene promoted tumorigenesis both in vitro and in vivo. a Expression of SNHG1 in MCF10A, Hs578T, MDA-MB-231, and MDA-MB-468 cell lines. b Transfection efficacy of siSNHG1 in MDA-MB-468, Hs578T, and MDA-MB-231 cells. c CCK-8 showed that silencing SNHG1 inhibited tumor cell proliferation. $\mathbf{d}$ Colony formation assay showed that silencing SNHG1 inhibited tumor cell clone formation. e Wound healing assay proved that silencing SNHG1 suppressed tumor cell migration. $\mathbf{f}$ Transwell invasion assay showed that knockdown of SNHG1 inhibited the invasion ability of tumor cells. $\mathbf{g}$ Knockdown efficacy of lentiviral targeting of snhg1. $\mathbf{h}$ CCK-8 showed that silencing of snhg 1 suppressed 4T1 proliferation. i Tumor growth curve of mice shows that sh-snhg1\#3 group had slower growth than that in the scramble group. $\mathbf{j}$ Tumor weight in the sh-snhg1\#3 group was lower than that in the scramble group. $\mathbf{k}$ The tumorigenesis and tumor tissue of each group of Balb/C mice $(\mathrm{N}=6 \mathrm{per}$ group) are shown. I The survival of scramble and sh-snhg1\#3 mice ( $N=6$ per group). Data are presented as the mean value from three independent experiments \pm S.D. ${ }^{*} P<0.05 ;{ }^{* *} P<0.01 ;{ }^{* * *} P<0.001 ;{ }^{* * * *} P<0.0001 ;$ NS no significance
} 


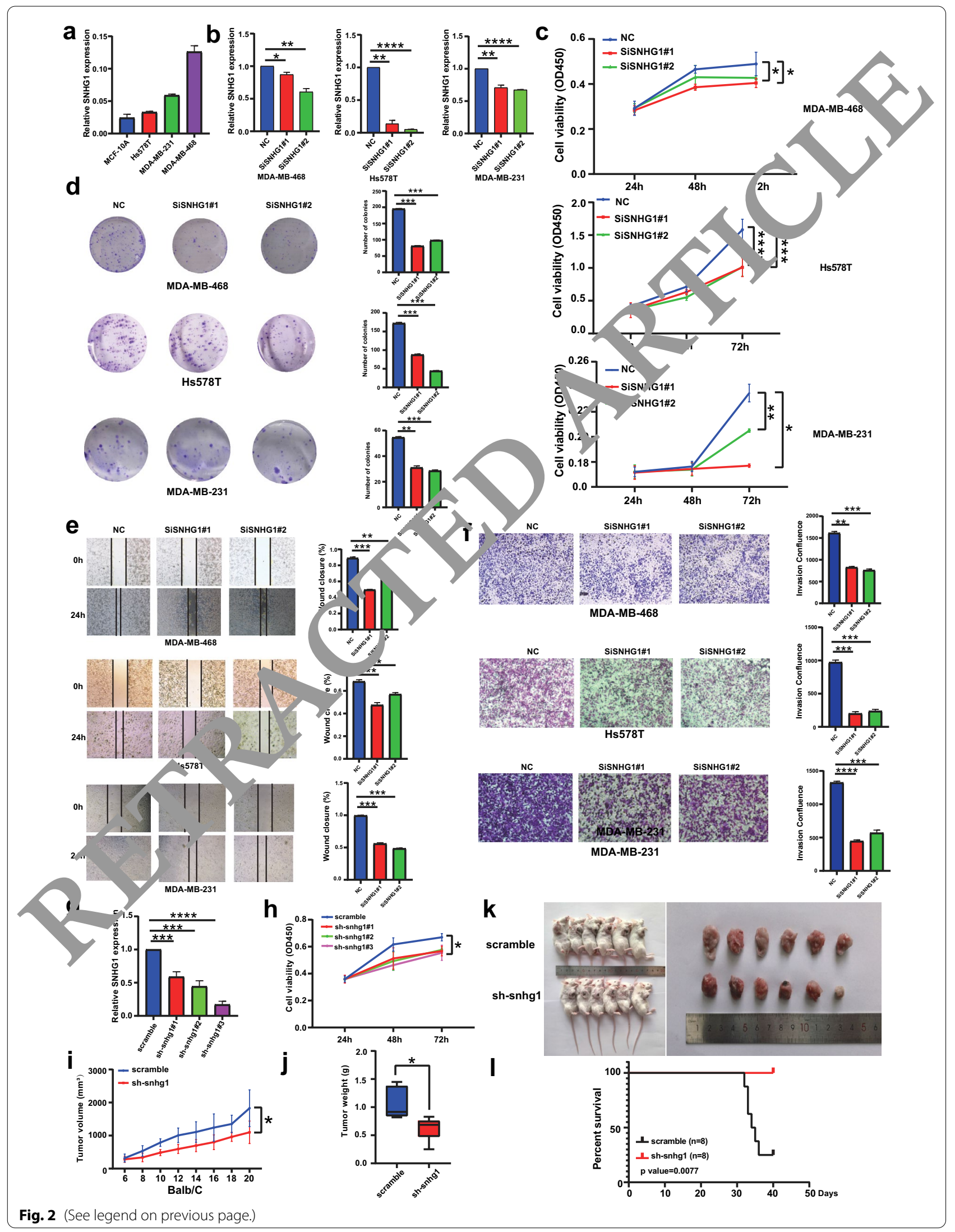


the function of TERT in breast cancer. We observed that silencing of TERT inhibited tumor cell proliferation and colony formation and tumor cell migration ability (Additional file 2: Fig. S2a-c).

SiSNHG1 was transfected into MDA-MB-468 and Hs578T, and RT-PCR was used to examine the transfection efficiency of siSNHG1 (Fig. 3i). Consequently, we observed that knockdown of SNHG1 downregulated the expression of TERT at both RNA (Fig. 3j) and protein levels (Fig. 3k) in MDA-MB-468 and Hs578T cells in comparison to their levels in corresponding control groups. To validate the regulatory axis through a contrasting approach, we also transfected SNHG1 overexpression plasmid to MDA-MB-468 and Hs578T. RT-PCR was used to confirm the transfection efficiency (Fig. 3l). The expression of TERT in RNA and protein level is upregulated in SNHG1 overexpression group compared to control group (Fig. 3m, n). Furthermore, for the in vivo experiment, we extracted protein and RNA from mouse tumors and observed that the expression level of TERT in mouse tumors was lower in the sh-snhg1\#3 group than in the control group (Fig. 3o).

Thus, SNHG1 promoted TERT expression in $D_{1}$, cancer. Next, we wondered whether targetin $\mathrm{SNHC}$ and TERT could produce a synergistic inhi ito effect BIBR1532 is a nonnucleotidic small mole le $\operatorname{com}_{\mathrm{H}}$ and that selectively inhibits telomerase ac vity by competitively binding to the active site of $\mathrm{h}^{\mathrm{T}} \mathrm{RT}^{\mathrm{C}} \mathrm{4}^{\prime}$. As we expected, the combination of 1 cking wown snhgl\#3 and administering the BIBR1532 (1) inhibitor) prohibited tumor growth mre po verfully than either approach alone (Fig. 3, q). The $n$.edian weight in the combination group as ver than that in the snhg1 knockdown grour contror oup (Fig. 3r).

miR-18b- 5 - tra as a tumor suppressor in breast cancer We fur er ex, 'or $d$ d the mechanism by which SNHG1 pro ote the expression of TERT in breast cancer.
First, LncLocator was used to predict the subcellular localization of SNHG1, and the results showed that SNHG1 was mainly localized in the cytoplasm, ro. 4a). Then, a cytoplasmic-nuclear RNA fracti tic.. kit was used to confirm the forward prediction m ylts in HEK293T, MDA-MB-468, and Hs578 cells (Fig 4b). Both methods implied that SNHG wa nain $y$ localized in the cytoplasm. Theref ore, we $h_{t}$ pothesized that cytoplasmic SNHG1 might egulate TERT mRNA by acting as a ceRNA of iRN 0 confirm this hypothesis, we used mir.oase, ngetScan, and starBase databases to predict a nossibl miRNAs that could interact with both SNHG and TERT, simultaneously (Additional file 8: - ble S6). The intersection of miRNAs acquired fr cum databases revealed 15 overlapping miRNAs (Fig. \%. RT-PCR was used to determine the upres ur. minNAs after silencing SNHG1 in MDA-MB-108 and Hs578T cells (Fig. 4d, e). Finally, miR-18b-5p and miR-383-5p were chosen for subsequer, xperiments. However, when miR-383-5p mimics rere $t$ ansfected into Hs578T cells, the expression of T. 7 was upregulated (Fig. 4f). Thus, miR-18b-5p was he only candidate for subsequent experiments. Moreover, after SNHG1 overexpression, the expression of miR-18b-5p also downregulated when compared with control group in MDA-MB-468 and Hs578T (Fig. 4g). To explore the functions of miR-18b-5p in breast cancer, we performed CCK-8, colony formation, wound healing, and Transwell invasion assays by transfecting Hs578T, MDA-MB-468, and MDA-MB-231 cells with miR-18b-5p mimics. The transfection efficiency of miR18b-5p mimics was verified by RT-PCR (Fig. 4h), and cell proliferation and colony formation were attenuated on transfecting miR-18b-5p mimics (Fig. 4i, j). Further, wound healing and Transwell invasion assays showed that overexpression of miR-18b-5p could inhibit tumor cell migration and invasion (Fig. $4 \mathrm{k}, \mathrm{l}$ ). Thus, the abovementioned experiments indicated that miR-18b-5p may act as a tumor suppressor in breast cancer.

\footnotetext{
(See figure on next page.)

Fig. 3 SNHG1 boosted TERT expression. TCGA data showed that TERT is positively correlated with SNHG1 in pan-caner $(\mathrm{N}=9725)(\mathbf{a})$ and in breast cancer $(\mathrm{N}=1097)(\mathbf{b})$. c GEPIA showed that TERT expression level was higher in breast cancer tissues than in normal tissues. $\mathbf{d}$, e We identified that TERT gene was upregulated expressed between high SNHG1 group and low SNHG1 group with FDR $=4.45785008467688 \mathrm{e}-19$, $F C=0.418132443350429$ in breast cancer. $\mathbf{f ~ G E P I A ~ s h o w e d ~ t h a t ~ t h e ~ e x p r e s s i o n ~ o f ~ T E R T ~ a ~ h i g h e r ~ l e v e l ~ i n ~ b r e a s t ~ c a n c e r ~ t i s s u e ~ t h a n ~ t h a t ~ i n ~ n o r m a l ~}$ tissue. $\mathbf{g}$ TERT presents a higher expression level in breast cancer cell lines than in MCF10A cell. $\mathbf{h}$ TERT showed higher expression level in breast cancer tissues than in paired normal tissues in our own cohort ( $N=4$ per group). $\mathbf{i}$ Transfection efficacy of siSNHG1. $\mathbf{j}$ Knockdown of SNHG1 downregulated TERT mRNA expression in Hs578T and MDA-MB-468 cells. Knockdown of SNHG1 also downregulated TERT protein expression in MDA-MB-468 and Hs578T cells (k). I The transfection efficiency of SNHG1 plasmid. $\mathbf{m}, \mathbf{n}$ The expression of TERT RNA and protein upregulated after SNHG1 overexpression. o TERT protein had a higher expression level in the scramble group than in the sh-snhg1\#3 group. p-r The tumorigenesis, tumor tissue, tumor growth and tumor weight of $4 \mathrm{~T} 1$ cells in each group of Balb/C mice ( $N=6$ per group) are shown. Data are presented as the mean value from three independent experiments \pm S.D. ${ }^{*} P<0.05 ;{ }^{* *} P<0.01 ;{ }^{* * *} P<0.001 ;{ }^{* * * * *} P<0.0001 ;$ NS no significance
} 


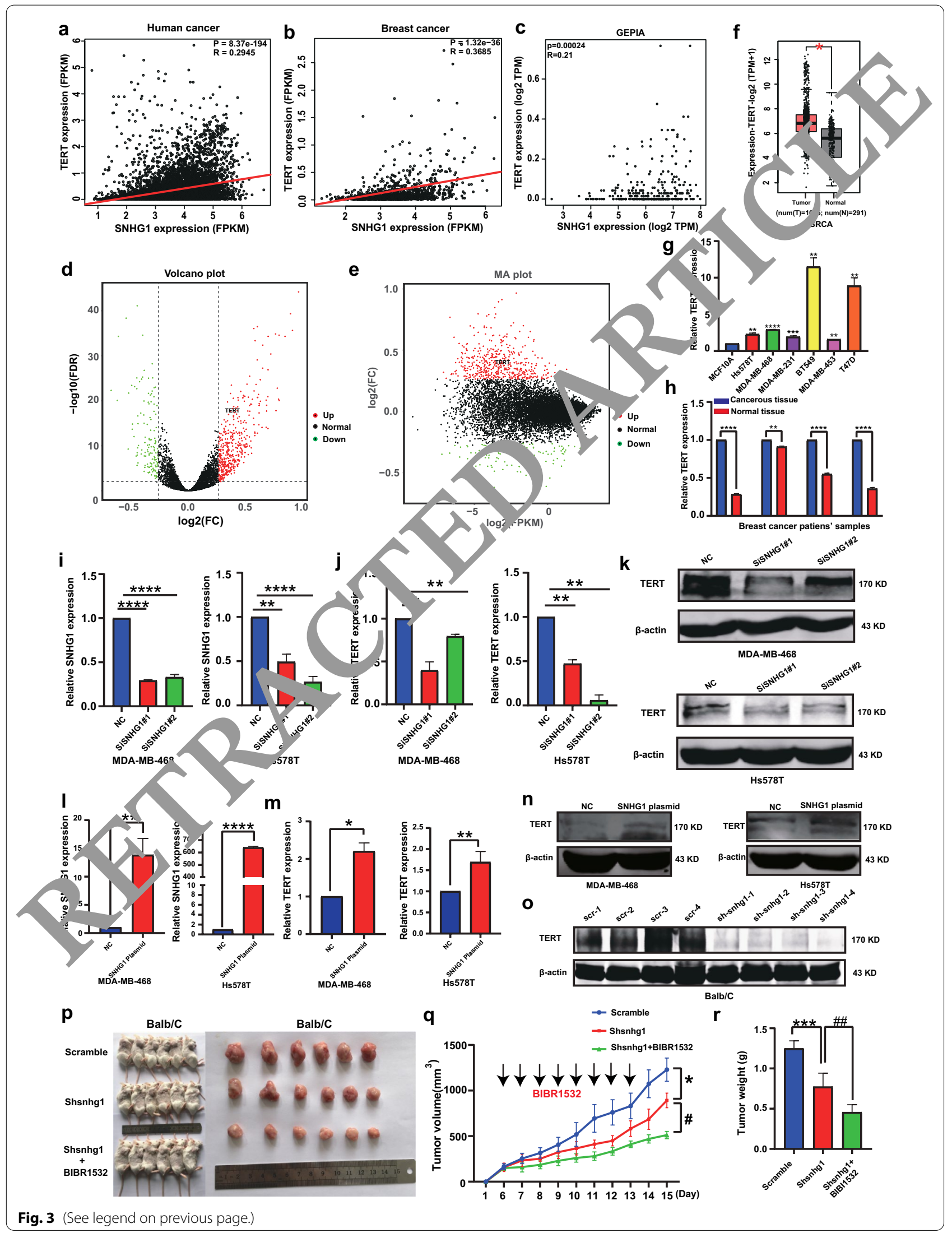




\section{SNHG1 acted as a ceRNA to enhance TERT expression by sponging miR-18b-5p}

We further explored the regulatory mechanism of SNHG1, miR-18b-5p, and TERT in breast cancer. RTPCR was used to evaluate the transfection efficiency of miR-18b-5p mimics (Fig. 5a). TERT RNA level was downregulated after transfecting miR-18b-5p mimics (Fig. 5b); whereas, the TERT RNA level was upregulated after transfecting miR-18b-5p inhibitor (Fig. 5d). Accordingly, TERT protein level was downregulated after transfecting miR-18b-5p mimics (Fig. 5c), and upregulated after transfecting miR-18b-5p inhibitor (Fig. 5e). Furthermore, overexpression of miR-18b-5p inhibited SNHG1 expression; however, downregulation of miR18b-5p promoted SNHG1 expression in MDA-MB-468 and Hs578T cells (Fig. 5f, g). Moreover, silencing SNHG1 and inhibiting miR-18b-5p weakened the downregulation of TERT protein level in MDA-MB-468 and Hs578T cells (Fig. 5h). Finally, the dual-luciferase reporter assay was used to demonstrate the binding relationship between SNHG1, miR-18b-5p, and TERT. As expected, wild-type 3 -untranslated region of TERT was regulated by m; $18 \mathrm{~b}-5 \mathrm{p}$, and this effect could be neutralized by $\mathrm{p}$ tating the binding sites in the luciferase reporter Fig. Additionally, we obtained similar results for regula tion of SNHG1 (Fig. 5j). SNHG1 function vas rtially mediated by inhibiting miR-18b-5p in b east cancer _ells. We transfected siSNHG1 and miR-18l 5p inhi bitor into breast cancer cells and observed that sis. $4 C$-mediated restraint in cell proliferation anc cion abilities could be partially rescued by co-trans a cio of miR-18b-5p inhibitor in Hs578T an $\mathrm{T}$. DA-M B-468 cells (Fig. 5k, 1). In addition, the expl ir f niR-18b-5p was more upregulated in in $\mathrm{ralD} / \mathrm{C}$. ice with snhg1 knockdown than in the scra $1 \mathrm{~b}$ roup $(\mathrm{N}=5)$ (Fig. $5 \mathrm{~m})$, which was consistent wi our pious conclusion. Thus, SNHG1 upregulate the xpression of TERT via a ceRNA mechanism by spon. ng $\mathrm{m}, \mathrm{R}-18 \mathrm{~b}-5 \mathrm{p}$ in breast cancer.

\section{$\mathrm{E} 2 \mathrm{~F} \mathrm{I}$}

\section{SNHG1 transcription}

We fur on focused on elucidating the upstream transcription regulation mechanism of SNHG1. First, PROMO database was used to predict potential transcription factors (TFs) that could bind to the SNHG1 promoter (Additional file 9: Table S7). We focused on E2F1, a prominent TF that mediates transcrintional activation in a variety of tumors. TCGA data as downloaded to evaluate the correlation between 1 a) $d$ SNHG1 in pan-cancer and breast carcer. The alts showed that E2F1 is positively correla 1 with SiNHG1 in pan-caner $(R=0.4129)$ and bre ot cance. $(\mathrm{P}=0.3521)$ (Fig. 6a and Additional file 10: ' able S8) To verify this prediction, we transfected $\mathrm{MDA}{ }^{\mathrm{B}} \mathrm{B}-4{ }^{\circ} 3$, Hs578T, and HEK293T cells with an s:RN to sirence E2F1. Knockdown efficiency was amined y RT-PCR (Fig. 6b) and western blotting ana, is (Fig. 6c). RT-PCR showed that the expressin evel of NHG1 (Fig. 6d) and TERT (Fig. 6e) in th E2 1 oroup was lower than that in the control group. $\mathrm{M}$ eover, the expression of miR-18b-5p is increa after s) encing E2F1 (Fig. 6f). Further, the JASPAR di ta',as was used to predict the potential binding site bet reen E2F1 and SNHG1 promotor (Fig. 6g, h, Au. inal file 11: Table S9). Finally, chromatin immunopre pitation-PCR assay indicated that in comparison th the Mock group, E2F1 was enriched at the SNHG1 pro noter in Hs578T and HEK293T cells (Fig. 6i). OverAl, we found a regulatory axis, E2F1-SNHG1-miR$18 \mathrm{~b}-5 \mathrm{p}-\mathrm{TERT}$, play a vital role in breast cancer. Then, we found that when silencing TERT in MDA-MB-468 and Hs578T, the expression of SNHG1 decreased and the expression of miR-18b-5p upregulated. There may be a circle regulation mechanism between SNHG1 and TERT in breast cancer which deserved to excavate in the future (Fig. 6j, k). A schematic illustration of this study is shown in Fig. 61.

\section{Discussion}

Numerous studies have highlighted the functions of these regulatory lncRNAs in many biological processes, such as cancer development, stem cell differentiation, and chemotherapy resistance [41]. For instance, lncHOST2 act as a sponge of let-7b, thus increasing STAT3 expression and leading to breast cancer tumorigenesis [42]. SNHG1 promotes tumor growth by regulating the transcription of both local and distal genes [43]. TERT boosts epithelial-mesenchymal

\footnotetext{
(See figure on next page.)

Fig. 4 miR-18b-5p acted as a tumor suppressor in breast cancer. a LncLocator predicted the subcellular localization of SNHG1. b Subcellular RNA fraction confirmed that SNHG1 was mainly located in the cytoplasm in HEK293T, MDA-MB-468, and Hs578T cells. c The intersection of TargetScan and StarBase predicted miRNAs. d, e The upregulated miRNAs after silencing of SNHG1 in MDA-MB-468 and Hs578T cells. f Expression of TERT after transfecting miR-383-5p mimics in Hs578T cells. $\mathbf{g}$ The expression of miR-18b-5p was downregulated after SNHG1 overexpression. $\mathbf{h}$ Transfection efficiency of miR-18b-5p mimics in Hs578T, MDA-MB-468, and MDA-MB-231 cells. i Colony counting kit-8 proved that miR-18b-5p inhibited cell proliferation. $\mathbf{j}-\mathbf{I}$ Colony formation assay, wound healing assay and Transwell invasion assay showed that miR-18b-5p inhibited breast cancer cell colony formation, migration and invasion. Data are presented as the mean value from three independent experiments \pm S.D. ${ }^{*} P<0.05 ;{ }^{*} P<0.01$; ***P $<0.001 ; * * * * * 0.0001$; NS no significance
} 


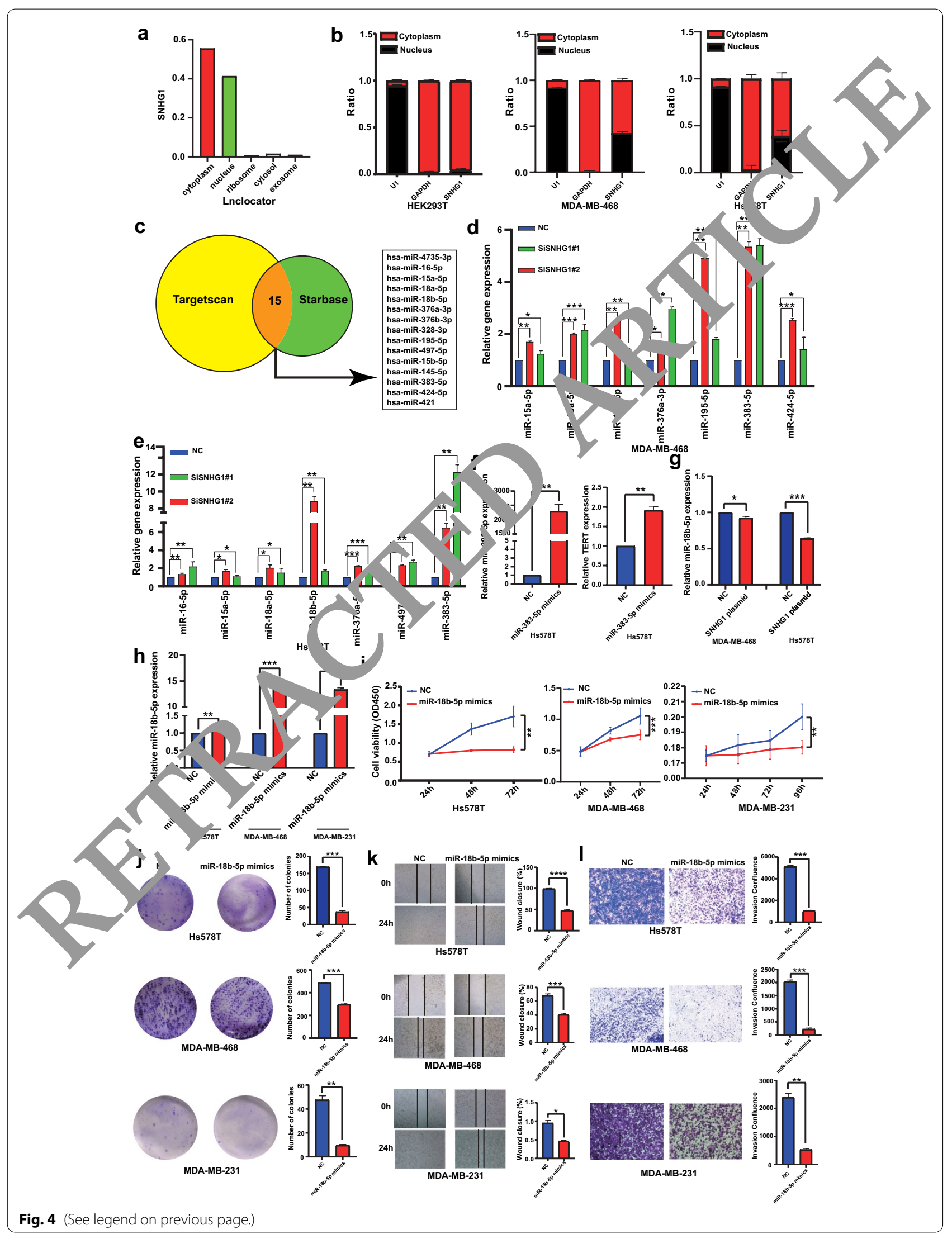


transformation and stemness, thereby indicating an important role in cancer progression [44]. This study revealed that SNHG1 was an oncogene that promoted the expression of TERT in breast cancer.

When lncRNAs are in the cytoplasm, they participate in modulating mRNA stability, regulating mRNA translation, serving as ceRNAs, and functioning as precursors of miRNAs [45]. Here, subcellular fractionation confirmed that SNHG1 was mainly located in the cytoplasm in breast cancer cell lines implying that SNHG1 acted as a ceRNA to enhance TERT expression by sponging miR-18b-5p in breast cancer.

To further explore the tumorigenesis mechanism of SNHG1 in breast cancer, we explored the upstream regulation of SNHG1. Notably, we observed that E2F1 could bind to the SNHG1 promoter and enhance its transcription in breast cancer. To summarize, this study uncovered a novel mechanistic axis, E2F1SNHG1-miR-18b-5p-TERT, in breast cancer tumorigenesis, and this axis may be a potential therapeutic target for breast cancer. In addition, the combination of SNHG1 knockdown and TERT inhibitor admir tration showed a synergistic inhibitory effect on 1 east cancer growth which may provide a potential her. for clinical therapy for breast cancer in $r$. future However, our study also has some limitations. irstly, TERT might only be one of the man targets of niR$18 \mathrm{~b}-5 \mathrm{p}$ and other targets gene shoul also bly studied in future. Secondly, we have not stu d he regulatory mechanism of SNHG1 wh nated in nucleus, and we will continue this study i rea future. Thirdly, although SNHG1 wac a ociard with shortened patients' survival, it re prognosis indepe dent other clinicopathological parameters, inc ad age, sex and TNM staging.

\section{Conclusion:}

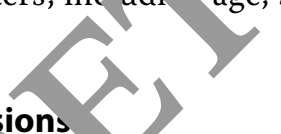

Our res lts io ntified a novel E2F1-SNHG1-miR$18 \mathrm{~b}-1$ axis, which may be a potential therapeutic $;$ et for breast cancer.

\section{Methods}

\section{Public data access and analysis}

Genome-wide SNHG1 expression profile and clinical pathology information for human cancers w re kownloaded from TCGA database (https://tcga-da aci.n . gov/2. The transcript SNHG1 was normalized $\log _{2}$ transformation. The expression of SNA 1 was tichotomized using a study-specific meran exp $c$ on as the cutoff to define "high value" at o above the median versus "low value" below the $\mathrm{r}$ "dia. The detailed clinical pathological information inc ling ID number, TNM stage of breast cancer atient fr 1 TCGA is shown in Additional file 3: Tab. S1. TEPIA database (http://gepia. cancer-pku.cn/) $\ldots$ TCGA atabase were used to predict the corre. on hotween SNHG1 and TERT; E2F1 and SNHG1 in p. cancer and breast cancer. Correlations bet gene were assessed by Pearson correlation coef $\mathrm{c} / \mathrm{nt} /$ Prognoscan (http://dna00.bio.kyute ch.ac.jp/Pro rnoScan/index.html) [46] and KM plotter

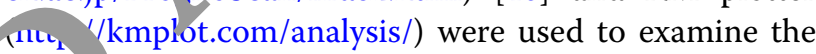
surviv $l$ of breast cancer patients according to differential 'HC 1 expression level. The expression profile of coding gete in breast cancer was extracted from TCGA BRCA ixpression profile (Additional file 7: Table S5). According to SNHG1 expression level, breast cancer tissue samples were divided into two groups. SNHG1 high expression group was found to be more than or equal to the median value of SNHG1, while SNHG1 low expression group was found to be less than the median value. Differentially expressed gene (DEG) was identified by edgeR between SNHG1 high expression and low expression group, of which FDR $<0.01, \mathrm{FC}>1.2$.

\section{Cell culture}

MDA-MB-468, Hs578T, HEK293T, MDA-MB-231 and 4T1 cell lines were obtained from the Chinese Academy of Sciences Cell Bank. MDA-MB-468, Hs578T, HEK293T and 4T1 were cultured with DMEM medium (Gibco, Waltham, MA) and 10\% fetal bovine serum (FBS; Gibco), $100 \mu / \mathrm{mL}$ penicillin and grown at $37{ }^{\circ} \mathrm{C}$ with $5 \% \mathrm{CO}_{2}$ (Thermo). MDA-MB-231 was cultured with L15 (Gibco,

\footnotetext{
(See figure on next page.)

Fig. 5 SNHG1 acted as a ceRNA to enhance TERT expression by sponging miR-18b-5p. a Transfection efficacy of miR-18b-5p mimics in MDA-MB-468 and Hs578T cells. b, c Overexpression of miR-18b-5p downregulated TERT mRNA and protein expression. d, e miR-18b-5p inhibitor upregulated TERT mRNA and protein expression. $\mathbf{f}, \mathbf{g}$ Overexpression of miR-18b-5p inhibited SNHG1 expression; however, downregulated miR-18b-5p promoted SNHG1 expression. $\mathbf{h}$ Silencing SNHG1 and inhibiting miR-18b-5p weakened the downregulation of TERT at the protein level in MDA-MB-468 and Hs578T cells. $\mathbf{i}$, j A luciferase reporter assay was used to assess the interactions between miR-18b-5p and its binding sites or mutated binding sites in the $3^{\prime}$ UTRs of TERT and SNHG1 in HEK293T cells. k, I siSNHG1-mediated restraint of cell proliferation and invasion abilities was partially rescued by co-transfection of miR-18b-5p inhibitor in Hs578T and MDA-MB-468 cells. m miR-18b-5p expression in Balb/C mice with snhg1 knockdown. Data are presented as the mean value from three independent experiments \pm S.D. ${ }^{*} P<0.05$; ${ }^{* *} P<0.01$; ${ }^{* * *} P<0.001$; ${ }^{* * * * *} P<0.0001$; NS no significance
} 


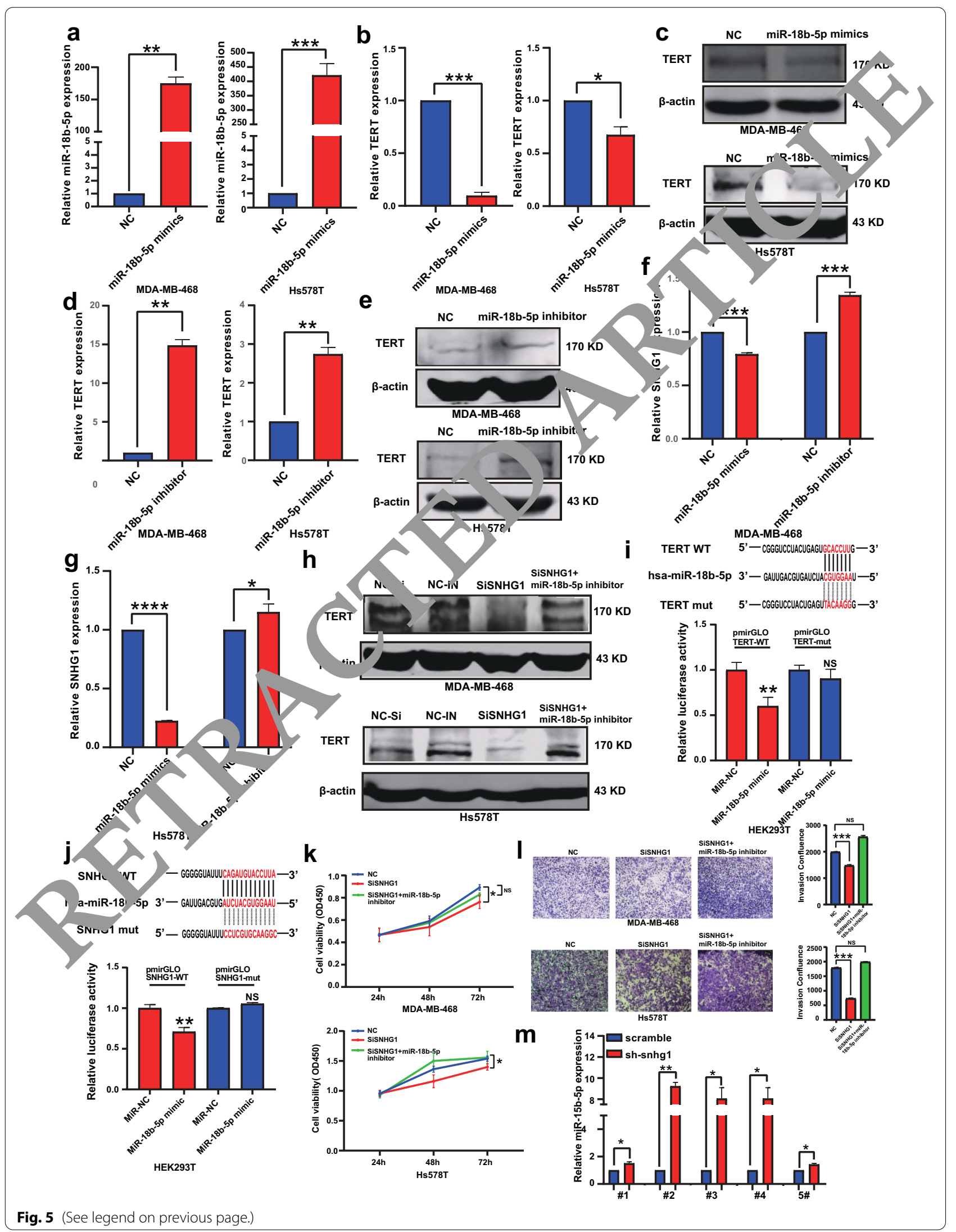




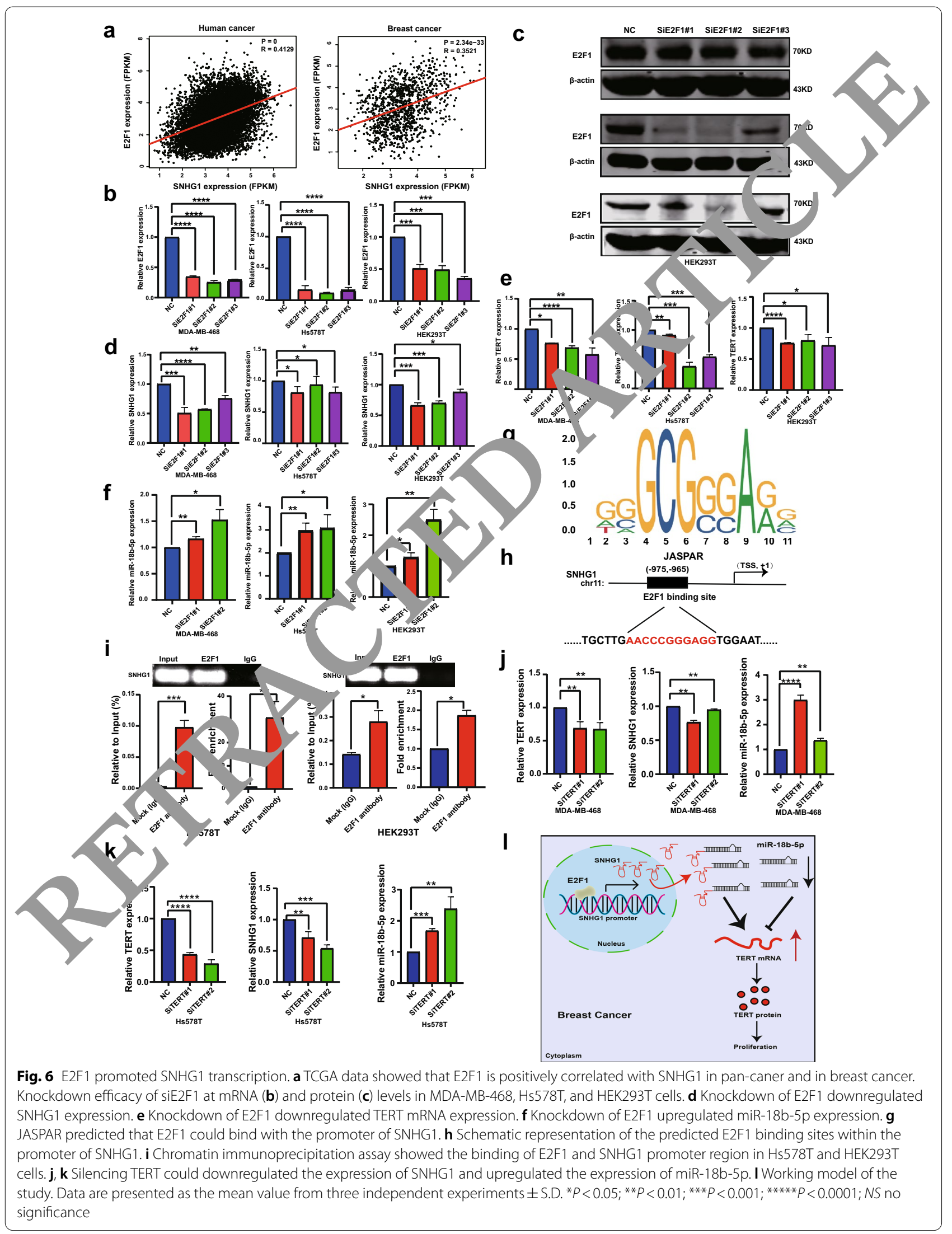


Waltham, MA) medium and $10 \% \mathrm{FBS}, 100 \mu / \mathrm{mL}$ penicillin and grown at $37^{\circ} \mathrm{C}$ with air incubator (Thermo).

\section{Patients and tissue specimens}

Breast cancer tissues and paired normal tissues were obtained from Harbin Medical University Cancer Center (HMUCC). None of the patients received adjuvant chemotherapy, immunotherapy, or radiotherapy before surgery, and patients with recurrent tumors, metastatic disease, bilateral tumors, or other previous tumors were excluded. For RNA extraction, fresh tissue from individuals with breast cancer and normal controls was collected and stored at $-80{ }^{\circ} \mathrm{C}$ immediately resection. The expression level of SNHG1 and TERT were measured by RT-qPCR. This study was approved by the Ethics Committees of Harbin Medical University. Written informed consent was obtained from all subjects who participated in this study.

\section{RNA extraction and RT-PCR}

Total RNA samples from cells samples were isolated using Trizol reagent (Invitrogen, USA) according 10 manufacturer's protocols. Total RNA $(0.5 \mu \mathrm{g})$ war hen reverse transcribed using Transcriptor First Stra cDNA Synthesis Kit (Roche, USA) to obtain a VA. The SYBR Green PCR Master Mix Kit (Applind Bios, tems, USA) was used to quantify the RNA 1 vels using ? YBR Green PCR Master Mix Kit, and the re: lts wer normalized against GAPDH and U6 expression using the $2^{-\Delta \Delta C T}$ method. The RT-qPCR va srformed on ABI StepOne Real-time PCR System App red Biosystems, USA). The primer sequenc are of follows: SNHG1F: 5'-AACTTCCCATA. 'TTC-3'; SNHG1-R: 5'-ACAACCAACA CAGCA CAC-3'; TERT-F: 5'-CTG TACTTTGTCA IG TGGAIGTGA-3'; TERT-R: 5'-ACGTGT2-TGGG TTTGATGATG-3'; Hsa-miR18b-5p-F: 5' SGGGCTAAGGTGCATCTAGTGC-3'; Hsa-miR-18b n-R 5'-ATCCAGTGCAGGGTCCGA GG- i a-mil 18b-5p-RT: 5'-GTCGTATCCAGTGCA GGL GGTCCGAGGTATTCGCACTGGATAC GACC ' 'CA-3'; Hsa-U6-F: 5'-GCTTCGGCAGCA CATATACTAAAAT-3'; Hsa-U6-R: 5'-CGCTTCACG AATTTGCGTGTCAT-3'; Hsa-U6-RT: 5'-CGCTTCACG AATTTGCGTGTCAT-3';

Hsa-miR-18a-5p-F: 5'-GCGGGCTAAGGTGCATCT AGTGC-3'; Hsa-miR-18a-5p-R: 5'-ATCCAGTGCAGG GTCCGAGG-3'; Hsa-miR-18a-5p-RT: 5'-GTCGTATCC AGTGCAGGGTCCGAGGTATTCGCACTGGATACG ACCTATCT-3'; Hsa-miR-376a-3p-F: 5'-CGGGCCGGA TCATAGAGGAAAAT-3'; Hsa-miR-376a-3p-R: 5'-ATC CAGTGCAGGGTCCGAGG-3'; Hsa-miR-376a-3p-RT: 5'-GTCGTATCC AGTGCAGGGTCCGAGGTATTC GCACTGGATACGACACGTGG-3'; Hsa-383-5p-F:
5'-GCGGGCAGATCAGAAGGTGATT-3'; Hsa-383-5pR: 5'-ATCCAGTGCAGGGTCCGAGG-3'; Hsa-383-5pRT: 5'-GTCGTATCCAGTGCAGGGTCCGAGGTATTC GCACTGGATACGACAGCCAC-3'; GAPDH- -5 : ${ }^{\prime}$-CAT GTTCGTCATGGGTGTGAA-3'; GAPDH-R: 5'-GG ATGGACTGTGGTCATGAG-3'; E2F1-F: $5^{\prime}$-AC TGA CGTGTCAGGACCT-3'; E2F1-R: 5'-GA 'GGGCCTTG TTTGCTCTT-3'; Mus-TERT-F: TGGTTGCC-3'; Mus-TERT-R: 5'-CAGCACGTTTCT CTCGTTGC-3'.

\section{Transfection of small int fering $R_{\imath}$, miRNA mimics/
inhibitors and plasmic.}

LncRNA SNHG hort is erfering RNA (siRNAs), Hsa-miR-18b- $\mathrm{m}$ mics and Hsa-miR-18b-5p inhibitor were synthes ad by Ribo Co., Ltd. (Guangdong, China). S Th1 pla mid (pcDNA3.1-SNHG1) was constructed b, Siar, nai GeneChem, Co. for SNHG1 overexpression. Cells were seeded in 6-well plate, when the -Crm row 70-80\% confluence for miRNA (100 nmol), siRNA $100 \mathrm{nmol})$, inhibitor $(50 \mathrm{nmol})$ and SNHG1 overt resion plasmid (2000 ng) transfection. Cells were tra sfected using jetPRIME (Polyplus transfection). The equences are as follows: si-control sense: UUCUCC GAACGUGUCACGUTT; si-SNHG1\#1 sense: GGU UUGCUGUGUAUCACAUTT; si-SNHG1\#2 sense: GAC CUAGCUUGUUGCCAAUTT; si-E2F1\#1 sense: GAG ACCTCTTCGACTGTGA; si-E2F1\#2 sense: CTATGA GACCTCACTGAAT; si-E2F1\#3: GGGAGAAGTCAC GCTATGA; si-TERT\#1 sense: GAGCCAGTCTCACCT TCAA; si-TERT\#2 sense: GGAGCAAGTTGCAAA GCAT; si-TERT\#3 sense: GAGTGACCGTGGTTTCTG T. Scrambled negative control mimics/inhibitor and microRNA (miR) 18b-5p-, miR-383-5p were purchased from Invitrogen (Invitrogen, CA, USA) and had the following sequences: Hsa-miR-18b-5p mimics sense: UAA GGUGCAUCUAGUGCAGUUAG antisense: AACUGC ACUAGAUGCACCUUAUU; Hsa-miR-18b-5p inhibitor sense: CUAACUGCACUAGAUGCACCUUA; Hsa-miR383-5p mimics sense: AGAUCAGAAGGUGAUUGU GGCU antisense: CCACAAUCACCUUCUGAUCUUU; has-18b-5p inhibitor sense: CUAACUGCACUAGAU GCACCUUA.

\section{Lentiviral transfection}

The full-length RNAi sequences and antisense were amplified by PCR and cloned into Lentiviral particles had puromycin selection and were constructed and packaged by Shanghai GeneChem, Co., Ltd. For lentiviral transfection, moderate lentiviruses were used to infect $4 \mathrm{~T} 1$ cells in a 6-well plate with $4-6 \mu \mathrm{g} / \mathrm{mL}$ polybrene (\#107689, Sigma). The infected cells were then subjected to selection with $1 \mu \mathrm{g} / \mathrm{mL}$ puromycin (\#540411, Calbiochem, 
USA) cultured for several days. The stable knockdown of snhg1 was examined by RT-PCR. The sequence of lentivirus as follows: sh-snhg1\#1: CTGGTGACAAATCTC AGGCAT; sh-snhg1\#2: GTGGTTCATCTCAAAGCC CTT; sh-snhg1\#3: AAGGATAGGAACAGAAATCAT.

\section{Cell viability assay}

The viability of treated cells was estimated by a Cell Counting Kit-8 (CCK-8; Dojindo Laboratories, Kumamoto, Japan) assay according to the manufacturer' instructions and as previous described [47]. Briefly, cells were plated at a density of $5 \times 10^{3}$ cells/well with $100 \mu \mathrm{L}$ of DMEM $+10 \%$ FBS in 96-well microtiter plates. $10 \mu \mathrm{L}$ CCK-8 solution was added to each well which including $100 \mu \mathrm{L}$ DMEM medium, and then the plate was incubated at $37{ }^{\circ} \mathrm{C}$ for $60 \mathrm{~min}$. Next, the absorbance of each well was measured by a microplate reader at a wavelength of $450 \mathrm{~nm}$. Medium containing 10\% CCK-8 served as a control.

\section{Colony formation assay}

$1 \times 10^{3}$ cells were seeded in 6-well plate and cultured medium containing $10 \%$ FBS for 14 days.

Discard the culture medium, PBS wash the 6- $t$. plate three times. Colonies were fixed with $\mathrm{m}$ ' anol for $40 \mathrm{~min}$, then $500 \mu \mathrm{L}$ of $5 \%$ crystal violet (Sis na- Arich, St. Louis, MO, USA) were added to eack weri for 30 , nin. After staining, colonies were gently was ed and pounted.

\section{Wound healing assay}

Cells were seeded in 6-well plate, tan, ected with siRNAs or miRNA mimics a ding to previous method. When cell confluence 10 h $10 \%, 10 \mu \mathrm{L}$ pipette was used to scratch on me bo $m$ of the 6-well plate. The scratched cells w re ashed way. Then taking photos in $0 \mathrm{~h}, 24 \mathrm{~h}, 48 \mathrm{~b}$

\section{Transwell inva on ac ay}

Tran we. invas, $\Lambda$ assay was performed using a Transwelt lo coning, New York, USA) was coated with Matrige 'Sigma-Aldrich, USA). $5 \times 10^{4}$ cells in serumfree mecium were suspended in upper chamber with Matrigel. Medium containing 20\% FBS (Seratech, PAN) was added to the bottom chamber. After incubating at $37{ }^{\circ} \mathrm{C}$ for $48 \mathrm{~h}$. Then discard the culture medium, cells that invaded to the lower side of the Transwell were fixed with methanol, stained with $0.5 \%$ crystal violet and imaged under a microscope. Image J was used to count the number of cells.

\section{Animal experiment}

Animal experiments were approved by the Medical Experimental Animal Care Commission of Harbin
Medical University. 4-5 weeks old female Balb/C mice were purchased from Animal Center of the Second Affiliated Harbin Medical University. 4T1 cells stably expressing sh-scramble and sh-snhg1\#3 were resuspe ded with DMEM medium. Then $100 \mu \mathrm{L}$ of serum-frec rediu ? containing $5 \times 10^{4}$ cells were injected into the righ $\quad 7 . \mathrm{m}$ mary fat pad. The tumor volume was 1 asurei with a caliper every 2 days beginning on uay 61 va after cell implantation. BIBR1532 was ad inistrated ntraperitoneally (i.p.) at a dose of $1.5 \mathrm{~m} / \mathrm{kg} \quad \mathrm{w}$ eks. The tumor volume was calculated uring he lon nula tumor volume $=1 / 2$ (length $\times$ wid $\left.h^{2}\right)$. The the mice were euthanized, the weight of um $s$ in mouse were measured. Then, half of the nors wa extracted protein and the other half was rac ed RNA.

\section{Western b assay}

Cells were ly on with lysis buffer which containing $150 \mathrm{mmol} / \mathrm{L} \mathrm{NaCl}, 1 \%$ Triton X-100, $5 \mathrm{mmol} / \mathrm{L}$ EDTA, $500 \mathrm{~J} / \mathrm{mL}$ aprotinin, $20 \mathrm{mg} / \mathrm{mL}$ leupeptin, $1 \mathrm{mmol} / \mathrm{L}$ pheny, methylsulfonyl fluoride, $2 \mathrm{mmol} / \mathrm{L}$ sodium choy anadate, $50 \mathrm{mmol} / \mathrm{L} \mathrm{NaF}, 5 \%$ glycerol, $10 \mathrm{mmol} / \mathrm{L}$ $\operatorname{Tr} 1-\mathrm{HCl}(\mathrm{pH}$ 7.4), and $2 \%$ SDS. Then ultrasonic crusher as used to broken cell nucleus. After centrifugation at $13,500 \times g$ for $30 \mathrm{~min}$, supernatant was collected. Next, protein concentrations were tested by BCA protein assay kit (\#p0010; Beyotime, Shanghai, China). Then these proteins were separated by SDS-PAGE, followed by electroblotting onto a nitrocellulose membrane, which was blocked with $5 \%$ nonfat milk in $0.1 \%$ Tween 20 -TBS overnight at $4{ }^{\circ} \mathrm{C}$. The membrane was incubated with primary antibody against TERT (\#sc-377511; Santa cruz biotechnology), E2F1 antibody (\#3742; Cell Signaling Technology) and $\beta$-actin (\#sc-377511; Santa cruz biotechnology). After washing with Tween 20/TBS (TBST), the membrane was incubated with horseradish peroxidase-conjugated secondary antibodies for $1 \mathrm{~h}$ in room temperature. After washing with Tween 20/PBS (PBST), protein bands on the membrane were visualized by an enhanced chemiluminescence Western blotting detection system (Western Lightning; Perkin-Elmer, Norwalk, CT).

\section{Dual-luciferase reporter gene assay}

We cloned the full length of the $3^{\prime}$ untranslated regions (UTRs) of human SNHG1 and TERT to generate reporter vectors with miRNA binding sites. The full length of $3^{\prime}$ UTRs of human SNHG1 and TERT were amplified by PCR and cloned into psi-CHECK-2 luciferase expression vector that contained Not1-Xhol sites. HEK293T cells were chosen to perform this assay. When $293 \mathrm{~T}$ reached 40-50\% confluence, JetPRIME was used to transfect HEK293T with $20 \mu \mathrm{mol} / \mathrm{L}$ Hsa-miR-18b-5p mimics or negative control mimics and $0.5 \mathrm{mg}$ of plasmid. The 
luciferase activities were measured $48 \mathrm{~h}$ after transfection using a dual-luciferase reporter assay kit (\#E1910, Promega, USA) and a luminometer (GloMax 20/20, Promega, USA).

\section{Cytoplasmic-nuclear RNA fractionation}

Cytoplasmic and nuclear RNA extraction were separated using the cytoplasmic and nuclear RNA purification kit (\#21000, NORGEN) as directed by the manufacturer. We harvested $3 \times 10^{6}$ cells (HEK293T, MDA-MB-468, and $\mathrm{Hs} 578 \mathrm{~T}$ ), washed them with ice-cold PBS, and then resuspended these cells in the ice-cold cytoplasmic Lysis Buffer $\mathrm{J}$ for $5 \mathrm{~min}$ on ice. Then lysates were centrifuged at $13,500 \times g$ for $10 \mathrm{~min}$ at $4{ }^{\circ} \mathrm{C}$. The supernatant was collected as the cytoplasmic fraction, the remaining lysates was collected as the nuclear fraction. Finally, cytoplasm RNA and nucleus RNA were successfully separated. Then, the expression levels of GAPDH, U1 and SNHG1 in cytoplasm or nuclear were detected by RT-PCR.

\section{Chromatin immunoprecipitation (ChIP)}

Chromatin immunoprecipitation (ChIP) assa th e performed using the ChIP Assay Kit (\#p2078, eyotime Shanghai, China) according to the manufacu vrer rotocol. $2 \times 10^{7}$ cells were crosslinked with $\%$ tormalde $y$ de, and this reaction was terminated aft $\mathrm{r} 20 \mathrm{~m} / \mathrm{n}$ by the addition of glycine at a final concentra $n-0.125 \mathrm{M}$. DNA was immunoprecipitatec $\urcorner m$ sonicated cell lysates using an E2F1 antibody; Ig $\mathrm{D}(\mathrm{BD}$, Siosciences, San Diego, CA, USA) served as e ne ative control. Protein A/G Plus-agarose was $p$ h from Santa cruz biotechnology (\#sc-2003). N Nase as Proteinase $\mathrm{K}$ treatment, immunoprecipit te DNA was extracted by DNA purification kit (Pyotime, rbanghai, China). The immunoprecipitate DN 4 was subjected to PCR to amplify the E2F1 promo bir ding sites. The amplified fragments were $\mathrm{ch}_{\text {, }}$ anal ed on an agarose gel. Chromatin (1\%) prio oprecipitation was used as the input control. Th vrimer sequences of binding site between E2F1 and SNHG1 was as follows: SNHG1-F: 5'-CAGGAGAAT TGCTTGAACCCG-3'; SNHG1-R: 5'-TGGCCCGAT CTCAGCTCACT-3'.

\section{Nucleic acid electrophoresis}

The DNA PCR products were investigated using 1\% agarose gel electrophoresis with TAE running buffer. DNA was separated by electrophoresis at $100 \mathrm{~V}$ for $30 \mathrm{~min}$. The DNA marker was Marker L (50-500 bp) (Sango Biotech, China). The bands were examined by UV irradiation (Biorad).

\section{Statistical analyses}

The expression of SNHG1 in cancer tissues compared with normal tissues were tested by a paired $t$-test. Kaplan-Meier method and log-rank test wer- used to evaluate the survival difference between $\mathrm{pat}_{\mathrm{a}}$, to wi h high SNHG1 expression and low SNHG1 express the differences in the results of the in vitro a $d$ in vi o experiments between groups were ana $/ \mathrm{a}$ a $\mathrm{u}$ student's $\mathrm{t}$-test. All the experiments we perform independently in triplicate. All staticica tests ere two-sided, and $P<0.05$ indicated statist, 1 slymicance. Statistical analysis was performe using ? R.3.4 graphics software and GraphPad I rish oftware (GraphPad Software, USA).

\section{Abbreviations}

ACC: Adreno carcino na; BLCA: Bladder urothelial carcinoma; BRCA: Breast carcino, na; _ _ell counting Kit-8; ceRNA: Competing endogenous RNA; CESC: Cer ' al anu endocervical cancers; ChIP: Chromatin immunoprecipitation; $\mathrm{CHOL}$. Cholangiocarcinoma; COAD: Colon adenocarcinoma; DEG: IITE. ially expressed gene; DSS: Disease specific survival; EMT: Epithelial mesenc mal transformation; ESCA: Esophageal carcinoma; HNSC: Head and ck squ mous cell carcinoma; GEPIA: Gene Expression Profiling Interactive A ${ }_{c} ;$, KICH: Kidney chromophobe; KIRC: Kidney renal clear cell carcinon, a; KIRP: Kidney renal papillary cell carcinoma; LIHC: Liver hepatocellular arcinoma; LncRNA: Long noncoding RNAs; LUAD: Lung adenocarcinoma; LUSC: Lung squamous cell carcinoma; miRNA: MicroRNA; ORF: Open reading frame; OS: Overall survival; PCPG: Pheochromocytoma and paraganglioma; PRAD: Prostate adenocarcinoma; READ: Rectum adenocarcinoma; RFS: Relapse free survival; SARC: Sarcoma; SiRNA: Short interfering RNA; SNHG1: Small nucleolar RNA host gene1; STAD: Stomach adenocarcinoma; TCGA: The Cancer Genome Atlas; TERC: Telomerase RNA component; TERT: Telomerase reverse transcriptase; TF: Transcription factor; THCA: Thyroid carcinoma; TNBC: Triple negative breast cancer; UCEC: Uterine corpus endometrial carcinoma; UTRs: Untranslated regions.

\section{Supplementary Information}

The online version contains supplementary material available at https://doi. org/10.1186/s13578-021-00675-5.

Additional file 1: Figure S1. a-c Higher expression level of SNHG1 was associated with poor overall survival, disease specific survival and progression free interval in UCEC. $\mathbf{d}-\mathbf{f}$ Higher expression level of SNHG1 was associated with poor disease specific survival, progression free interval and disease-free interval in LIHC. $\mathbf{g}$-i Higher expression level of SNHG1 was associated with poor overall survival, disease free interval and progression free interval in PRAD. $\mathbf{j}-\mathbf{k}$ Higher expression level of SNHG1 was associated with poor overall survival and progression free interval in ACC. I-o Higher expression of SNHG1 was correlated with poor OS in LIHC, KIRC, SARC and UCEC.

Additional file 2: Figure S2. CCK-8 (a), wound healing (b) and colony formation assays (c) were performed to identify that silencing of TERT inhibited tumor cell proliferation and colony formation and suppressed tumor cell migration and invasion in MDA-MB-468 and Hs578T.

Additional file 3: Table S1. The clinical pathology information of the breast cancer tissues in the TCGA analysis for SNHG1 expression level.

Additional file 4: Table S2. SNHG1 expression and prognosis of human pan-cancer in TCGA database.

Additional file 5: Table S3. Regarding the primary samples $(n=5)$ validating the SNHG1 and TERT expression, patient demographic data were provided. 
Additional file 6: Table S4. The relationship between expression of SNHG1 and TERT of human pan-cancer in TCGA database.

Additional file 7: Table S5. The expression profile of coding gene in breast cancer was extracted from TCGA BRCA expression profile.

Additional file 8: Table S6. TargetScan, and starBase databases to predict the possible miRNAs that could interact with both SNHG1 and TERT, simultaneously.

Additional file 9: Table S7. PROMO database was used to predict potential transcription factors (TFs) that could bind to the SNHG1 promoter.

Additional file 10: Table S8. The relationship between expression of E2F1 and SNHG1 of human pan-cancer in TCGA database.

Additional file 11: Table S9. JASPAR database was used to predict the potential binding site between E2F1 and SNHG1 promotor.

\section{Acknowledgements}

None.

\section{Authors' contributions}

Conceptualization, XSP and KYJ; data curation, KYJ, LL, LJN, YYL, ZL and ZX; data analysis, WL, YYL; writing-original draft preparation, KYJ; writing-review and editing, PD, XSP, WQ; funding acquisition, PD, XSP and WQ. All authors read and approved the final manuscript.

\section{Funding}

This work was supported by funding from the Project Nn10 of Harbin Me alcal University Cancer Hospital (Grant Number Nn102017-02), the Nati Natural Science Foundation of China (Grant Numbers 82072904, 81072 1. 81972706, 82103325), Outstanding Youth Project of Heilongjian Provincial Natural Science Foundation (Grant Number YQ2019H027), D; ith, ished Young Scholars of Harbin Medical University Cancer Hospital Gran, 'mber JCQN2018-03), Yong Elite Training Foundation Grant of 1 Tarom Medicar (1)versity Cancer Hospital (Grant Number JY2016-02) ar Haiyan Fund Project of Harbin Medical University Cancer Hospital (Grant nu er JJQN 7 D18-10).

Availability of data and materials
All remaining data are availability within the ticle ditional files, or available from the authors upon request.

\section{Declarations}

\section{Ethics approval and on th to parti - pate}

All animal experiment. were, rformed in accordance with the National Institutes of Hea' in guide for thy are and use of Laboratory animals and protocols appro' by th Animal Ethics Committee of Harbin Medical University of Medicine and alth SC nces. The use of breast cancer tissue samples was ap d and $h$ ized by the Ethics Committee of Harbin Medical Uni rsity $C$ Medicin and Health Sciences. Both the patient and his family mem led the informed notice and informed consent of tissue use. All b viors conform to laws, regulations and rules.

\section{Consent for publication}

All author shave agreed to publish this manuscript.

\section{Competing interests}

The authors declare no conflict of interest.

\section{Author details}

${ }^{1}$ Department of Breast Surgery, Harbin Medical University Cancer Hospital, Harbin 150040, China. ${ }^{2}$ Heilongjiang Academy of Medical Sciences, Harbin, China.

Received: 27 February 2021 Accepted: 3 August 2021

Published online: 31 August 2021

\section{References}

1. Lee S, Kopp F, Chang TC, Sataluri A, Chen B, Sivakumar S, et al. Noncoding RNA NORAD regulates genomic stability by sequestering PIJMILIO proteins. Cell. 2016;164(1-2):69-80.

2. Niazi F, Valadkhan S. Computational analysis of function ng n $\mathrm{n}$ coding RNAs reveals lack of peptide-coding capacity and paralı ' vith $3^{\prime}$ UTRs. RNA. 2012;18(4):825-43.

3. Zhao J, Song X, Wang K. IncScore: alignment-fre entificatien d long noncoding RNA from assembled novel ransc 2016;6(1):1-12.

4. Jia H, Osak M, Bogu GK, Stanton LW, Jor son R, Lipqvich L. Genome-wide computational identification and manuc nnotatic 1 of human long noncoding RNA genes. RNA. 201, (8):14

5. Saha A, Bhattacharya S, Bhat charya Serum stress responsive gene EhslncRNA of Entamoeba tolytica is a long noncoding RNA. Sci Rep. 2016;6(1):1-9.

6. Gibb EA, Brown CJ, Lam WL. The nctional role of long non-coding RNA in human carcins illa. Mol Cance 2011;10(1):1-17.

7. Spizzo R, Alms MI, alombatti A, Calin GA. Long non-coding RNAs and cancer. ew rumier of translational research? Oncogene. 2012;31(43):4577-8>

8. Bhan A ani M, Landal SS. Long noncoding RNA and cancer: a new paradign C:ric es. 2017;77(15):3965-81.

9. Verhoeve, RJA, Tong S, Mok BW, Liu J, He S, Zong J, et al. Epstein-Barr virus BART 19 non-coding RNAs function as epigenetic modulators in

opharyngeal carcinoma. Front Oncol. 2019;9:1120.

10. Zh ig J, Sui S, Wu H, Zhang J, Zhang X, Xu S, et al. The transcriptional lan iscape of IncRNAs reveals the oncogenic function of LINC00511 in F,-negative breast cancer. Cell Death Dis. 2019;10(8):599.

11 Salmena L, Poliseno L, Tay Y, Kats L, Pandolfi PP. A ceRNA hypothesis: the Rosetta Stone of a hidden RNA language? Cell. 2011;146(3):353-8.

12. Achkar NP, Cambiagno DA, Manavella PA. miRNA biogenesis: a dynamic pathway. Trends Plant Sci. 2016;21(12):1034-44.

13. Karreth FA, Tay Y, Perna D, Ala U, Tan SM, Rust AG, et al. In vivo identification of tumor-suppressive PTEN ceRNAs in an oncogenic BRAF-induced mouse model of melanoma. Cell. 2011;147(2):382-95.

14. Tay Y, Kats L, Salmena L, Weiss D, Tan SM, Ala U, et al. Coding-independent regulation of the tumor suppressor PTEN by competing endogenous mRNAs. Cell. 2011;147(2):344-57.

15. Yan Y, Fan Q, Wang L, Zhou Y, Li J, Zhou K. LncRNA Snhg1, a non-degradable sponge for miR-338, promotes expression of proto-oncogene CST3 in primary esophageal cancer cells. Oncotarget. 2017;8(22):35750-60.

16. Li J, Zhang Z, Xiong L, Guo C, Jiang T, Zeng L, et al. SNHG1 IncRNA negatively regulates miR-199a-3p to enhance CDK7 expression and promote cell proliferation in prostate cancer. Biochem Biophys Res Commun. 2017:487(1):146-52.

17. Wang Q, Li Q, Zhou P, Deng D, Xue L, Shao N, et al. Upregulation of the long non-coding RNA SNHG1 predicts poor prognosis, promotes cell proliferation and invasion, and reduces apoptosis in glioma. Biomed Pharmacother. 2017;91:906-11.

18. Liu L, Shi Y, Shi J, Wang H, Sheng Y, Jiang Q, et al. The long non-coding RNA SNHG1 promotes glioma progression by competitively binding to miR-194 to regulate PHLDA1 expression. Cell Death Dis. 2019;10(6):463.

19. Cui L, Dong Y, Wang X, Zhao X, Kong C, Liu Y, et al. Downregulation of long noncoding RNA SNHG1 inhibits cell proliferation, metastasis, and invasion by suppressing the Notch-1 signaling pathway in pancreatic cancer. J Cell Biochem. 2019;120(4):6106-12.

20. Pei $X$, Wang $X$, Li H. LncRNA SNHG1 regulates the differentiation of Treg cells and affects the immune escape of breast cancer via regulating miR448/IDO. Int J Biol Macromol. 2018;118(Pt A):24-30.

21. Xiong $X$, Feng $Y$, Li L, Yao J, Zhou M, Zhao P, et al. Long noncoding RNA SNHG1 promotes breast cancer progression by regulation of LMO4. Oncol Rep. 2020;43(5):1503-15.

22. Li J, Zeng T, Li W, Wu H, Sun C, Yang F, et al. Long non-coding RNA SNHG1 activates HOXA1 expression via sponging miR-193a-5p in breast cancer progression. Aging. 2020;12(11):10223-34.

23. Zheng S, Li M, Miao K, Xu H. SNHG1 contributes to proliferation and invasion by regulating miR-382 in breast cancer. Cancer Manag Res. 2019;11:5589-98. 
24. Blackburn EH. Switching and signaling at the telomere. Cell. 2001;106(6):661-73.

25. Moyzis RK, Buckingham JM, Cram LS, Dani M, Deaven LL, Jones MD, et al. A highly conserved repetitive DNA sequence, (TTAGGG)n, present at the telomeres of human chromosomes. Proc Natl Acad Sci USA. 1988;85(18):6622-6.

26. Makarov VL, Hirose Y, Langmore JP. Long $G$ tails at both ends of human chromosomes suggest a C strand degradation mechanism for telomere shortening. Cell. 1997;88(5):657-66.

27. Greider CW, Blackburn EH. A telomeric sequence in the RNA of tetrahymena telomerase required for telomere repeat synthesis. Nature. 1989:337(6205):331-7.

28. Lendvay TS, Morris DK, Sah J, Balasubramanian B, Lundblad V. Senescence mutants of Saccharomyces cerevisiae with a defect in telomere replication identify three additional EST genes. Genetics. 1996;144(4):1399-412.

29. Lingner J, Cech TR. Purification of telomerase from Euplotes aediculatus: requirement of a primer $3^{\prime}$ overhang. Proc Natl Acad Sci USA. 1996;93(20):10712-7.

30. Cong YS, Wright WE, Shay JW. Human telomerase and its regulation. Microbiol Mol Biol Rev. 2002;66(3):407-25 (table of contents).

31. Li C, Wu MY, Liang YR, Wu XY. Correlation between expression of human telomerase subunits and telomerase activity in esophageal squamous cell carcinoma. World J Gastroenterol. 2003;9(11):2395-9.

32. Yi X, Tesmer VM, Savre-Train I, Shay JW, Wright WE. Both transcriptional and posttranscriptional mechanisms regulate human telomerase template RNA levels. Mol Cell Biol. 1999;19(6):3989-97.

33. Kim NW, Piatyszek MA, Prowse KR, Harley CB, West MD, Ho PL, et al. Specific association of human telomerase activity with immortal cells and cancer. Science. 1994;266(5193):2011-5.

34. Cukusic A, Vidacek NS, Sopta M, Rubelj I. Telomerase regulation at crossroads of cell fate. Cytogenet Genome Res. 2008;122(3-4)·263-

35. Siegel RL, Miller KD, Jemal A. Cancer statistics, 2016. CA Can er J́lin. 2016;66(1):7-30.

36. Chen W. Cancer statistics: updated cancer burden in Ch. na. C. Y Cancer Res. 2015;27(1):1.
37. Breast Cancer Treatment (Adult) (PDQ(R)): Patient Version, in PDQ Cancer Information Summaries. 2002: Bethesda (MD).

38. Elkak A, Mokbel R, Wilson C, Jiang WG, Newbold RF, Mokbel K. hTERT mRNA expression is associated with a poor clinical outcome Amuman breast cancer. Anticancer Res. 2006;266C:4901-4.

39. Nagy A, Lanczky A, Menyhart O, Gyorffy B. Validation of mil vognd tic power in hepatocellular carcinoma using expression data of is ver aent datasets. Sci Rep. 2018;8(1):9227.

40. Pascolo E, Wenz C, Lingner J, Hauel N, Priepke H, Ko fmann I t al. Mechanism of human telomerase inhibiti n, BIBR, a synthetic, non-nucleosidic drug candidate. J Biol C iem. 2002;277( )):15566-72.

41. Adams BD, Parsons C, Walker L, Zhang V Slack FJ. Jargeting noncoding RNAs in disease. J Clin Invest. 2017 273: 71.

42. Hua K, Deng $X$, Hu J, Ji C, Yu Y, L J, e Long muncoding RNA HOST2, working as a competitive e dogenous IA promotes STAT3-mediated cell proliferation and mis a via decoy ig of let-7b in triple-negative breast cancer. J Exp Clir Cance

43. Sun Y, Wei G, Luo H, W, Skoge, G, Luo J, et al. The long noncoding RNA SNHG1 prr note, umor growth through regulating transcription of both local and a l, incogene. 2017;36(49):6774-83.

44. Yuan $X$, Larsson $C$, $>$ Mechanisms underlying the activation of TERT transch and telor erase activity in human cancer: old actors and new plate's.

45. Rashid F, bah A, wan G. Long non-coding RNAs in the cytoplasm. Genom Pr teom Bioinform. 2016;14(2):73-80.

izuno H, wada K, Nakai K, Sarai A. PrognoScan: a new database for in a-analysis of the prognostic value of genes. BMC Med Genom. 20 ) $; 2(1): 1-11$

Kl olodenko BN, Demin OV, Moehren G, Hoek JB. Quantification of short lerm signaling by the epidermal growth factor receptor. J Biol Chem. 1999:274(42):30169-81.

\section{Publisher's Note}

Springer Nature remains neutral with regard to jurisdictional claims in published maps and institutional affiliations.

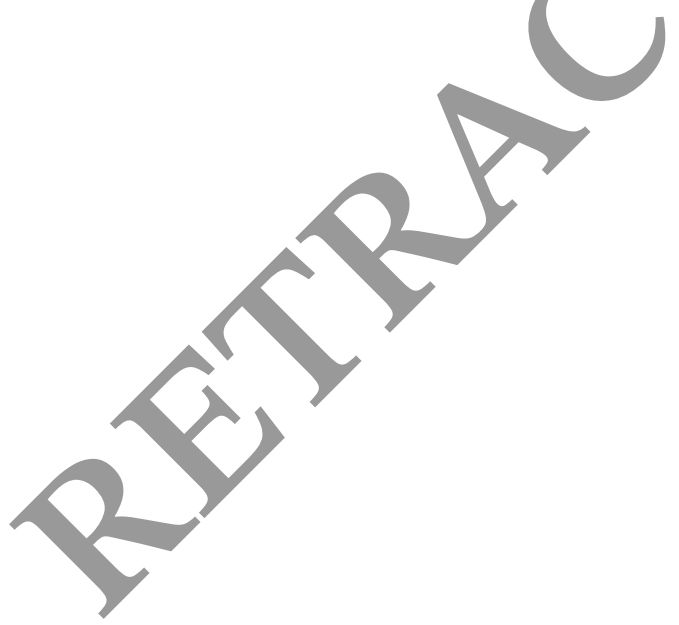

Ready to submit your research? Choose BMC and benefit from:

- fast, convenient online submission

- thorough peer review by experienced researchers in your field

- rapid publication on acceptance

- support for research data, including large and complex data types

- gold Open Access which fosters wider collaboration and increased citations

- maximum visibility for your research: over $100 \mathrm{M}$ website views per year

At BMC, research is always in progress.

Learn more biomedcentral.com/submissions 